\title{
A review of the biological and physical mechanisms underlying aortic aneurysm pathology
}

Itai Palmon* and Michal Zochowski, PhD

University of Michigan Department of Biophysics, 930 N University Ave, Ann Arbor MI 48109

\section{Introduction}

The thoracic aortic aneurysm (TAA) is a well-documented disease, noted as casual reference as far back as 1885 in literature. ${ }^{1}$ It is characterized by a pathological and progressive dilatation of the thoracic aorta, and is severe for its propensity towards the fatal consequences of aortic dissection and rupture. The prevalence of the disease is estimated between 0.16 and 0.34 percent, but is likely understated due to the silent nature of the disease. ${ }^{2,3}$ Vessel dilation, unless rapid, produces no pain for the patient, and the associated development of aortic valve regurgitation typically presents only with advanced aortic dilation. A common method for assessing aortic pathology is echocardiography, which uses ultrasound to measure aortic diameter. In normal male and female adults, values for aortic root diameter range from 2 to $3 \mathrm{~cm} .{ }^{4}$ The only lasting intervention is prophylactic surgical replacement of the aorta with a synthetic graft, and values suggestive of surgery range from 3.5 to $8 \mathrm{~cm}$, depending on factors including body surface area (BSA), rate of aortic expansion ( $\mathrm{mm} /$ year), and various predisposing genetic factors. ${ }^{5,6}$ Further, TAAs may present in various locations along the aorta with differing incidence, at the root or ascending region of the aorta $(40 \%)$, aortic arch $(15 \%)$, descending thoracic aorta $(35 \%)$, or thoracoabdominal aorta $(10 \%){ }^{7}$

TAAs may present in three general cases. The aneurysm may be non-syndromic, where the patient has no detectable associated genetic disease. It may be connected to Bicuspid Aortic Valve disorder (BAV), which has a considerable incidence, but a largely undefined genetic basis in the current understanding of the disease. Most commonly, TAAs pres-

\footnotetext{
* To whom correspondence should be addressed: ipalmon@umich.edu
}

ent with association to one of several hereditary mutations linked by their common pathophysiological mechanism through transforming growth factor beta (TGF- $\beta$ ), chiefly Marfan syndrome (MFS) and Loeys-Dietz syndrome (LDS). $8,9,10,11,12,13$

The mechanism of TAA development is not currently well-understood. However, the disease is fundamentally, and at times paradoxically, both physical and biological in nature. For example, extensive evidence describes elevated blood pressure as causative of aortic wall stress and strain, and vascular dilation. ${ }^{14,15,16}$ More, a landmark study on MFS aortic root aneurysm development showed that targeted intervention of a specific cell-signaling pathway via Losartan, an angiotensin II receptor blocker, was more effective in attenuating aneurysm growth than treatment with atenolol, a beta-blocker with similar effects to Losartan in reducing blood-pressure. ${ }^{17}$

This review will explore the biological and physical underpinnings of TAA development, and elaborate on the apparent dichotomy between physical and biological explanations of the disease, in hopes of promoting a more comprehensive and interdisciplinary approach to the topic.

\section{Physical Basis For Aneurysm Dilatation}

This section will serve to elucidate the theoretical approach to the aortic aneurysm and its exacerbation, in terms of physical quantities and principles.

\subsection{Principle of Continuity}

$$
u_{1} A_{1}=u_{2} A_{2}
$$


Net flux of blood in a vessel can be approximated using the product of the fluid's average velocity, $u$, and the area in which it is passing, $A .{ }^{19}$ According to the principle of continuity, this flux must be equal on either side of a changing area within a closed system (Equation 1). That is, a decrease in the cross-sectional area $A$ of a vessel-proportional to the square of its diameter-will result in an elevated velocity of the fluid. Conversely, and in the case of aneurysmal dilation of a vessel, an increased $A$ results in decreased blood velocity across the dilated region.

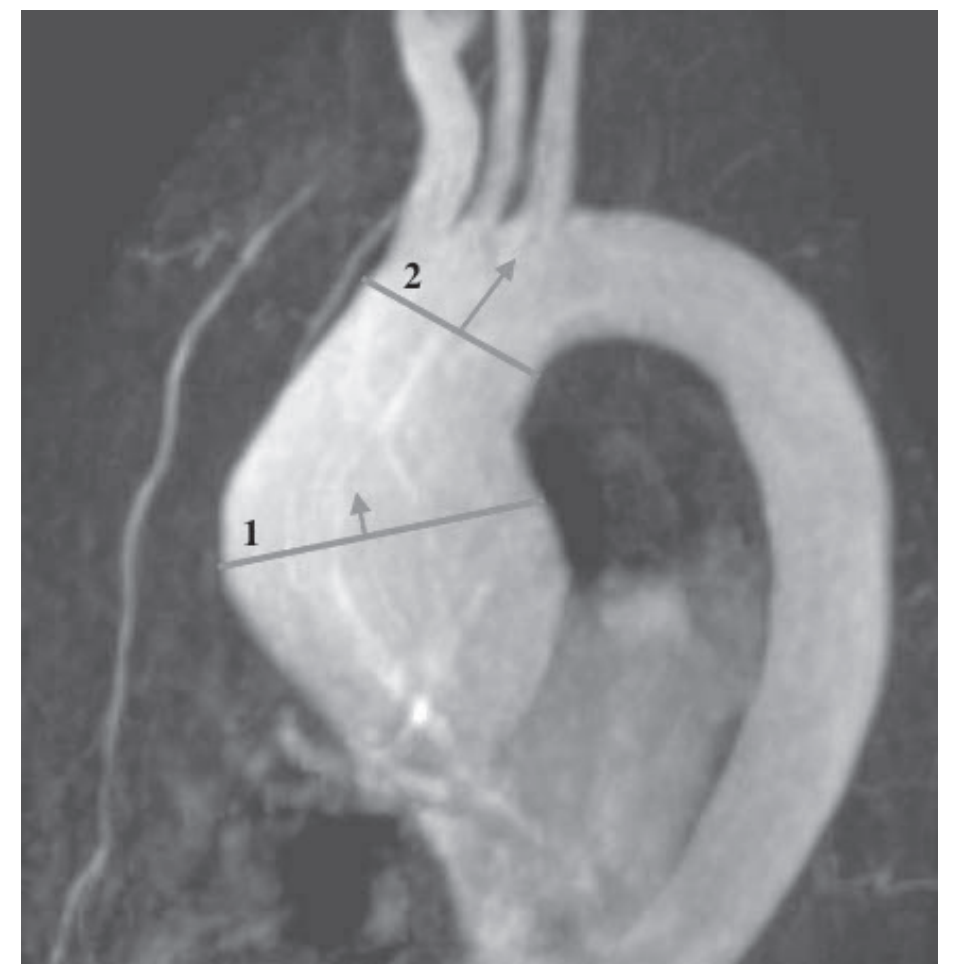

Figure 1. Magnetic Resonance Imaging (MRI) of an ascending aortic aneurysm depicting a dilated section of lower velocity (1) and a section of relative higher velocity (2). Image referenced from "Cardiac Imaging: A Multidisciplinary Approach"18

\subsection{Bernoulli Equation}

This equation relates the pressure, $P$, of a fluid system with the velocity, $v$, density, $\rho$, and height, $h$ therein.

$$
P_{1}+\rho g h_{1}+\frac{1}{2} \rho v_{1}^{2}=P_{2}+\rho g h_{2}+\frac{1}{2} \rho v_{2}^{2}
$$

Assuming negligible change in density and height of blood in a person, and substituting $K$ for $\frac{1}{2} \rho$ :

$$
\begin{gathered}
P_{1}+K v_{1}^{2}=P_{2}+K v_{2}^{2} \\
P_{1}-P_{2}=K\left(v_{2}^{2}-v_{1}^{2}\right) \\
P_{1}-P_{2} \propto v_{2}^{2}-v_{1}^{2}
\end{gathered}
$$

According to the principle of continuity, the velocity of blood in the dilated section of the aorta is lower than that of the healthy section (Equation 1). Therefore, $v_{2}>v_{1}$, and $v_{2}^{2}-v_{1}^{2}>0$. In accordance with the proportionality between pressure and velocity derived above, $P_{1}-P_{2}$ must be a positive expression if $v_{2}^{2}-v_{1}^{2}>0$, and $P_{1}$ must consequently be larger than $P_{2}$. (Equation 5). That is, the decreased velocity of blood within the dilated region results in an increase of pressure within the same region. One limitation of this approach is that the Bernoulli equation assumes flow to be wholly laminar. Aortic blood flow, however, is often turbulent, containing particles of the fluid which hold scattered velocity vectors, i.e. kinetic energy which does not contribute to the forward motion of the fluid. This notion will be discussed further in section 2.4.

In summation, using the principle of continuity and the Bernoulli equation, an increase in radius of the aorta leads to lower velocity and increased pressure on the arterial wall, within the dilated region (Equations 1, 5).

\subsection{Laplace Equation}

$$
T=\frac{1}{2} P \times R
$$

The Young-Laplace equation is important for relating the contributions of both pressure, $P$, and radius, $R$, to tension, $T$, on an arterial wall. In a hollow spherical vessel, an apt model for an aneurysmal blood vessel due to its "ballooning" character, the Laplace equation explains that wall tension is equal to half of the product of the cylinder's radius and internal pressure. ${ }^{21}$ Pairing this with the prior results of sections 2.1 and 2.2, that increasing arterial radius causes increasing pressure, it is shown that arterial wall tension is exacerbated by the presence of an aneurysm through multiple physical descriptors which affect one another. Further, in a genetically "weak," artery which lacks the elasticity necessary for maintaining its structural integrity, the relationship between pressure, radius, and tension may be viewed as analogous to positive feedback in biological systems, where increased pressure with inadequate tension results in a further increase in radius - in turn, increasing the pressure, and so on and so forth. 


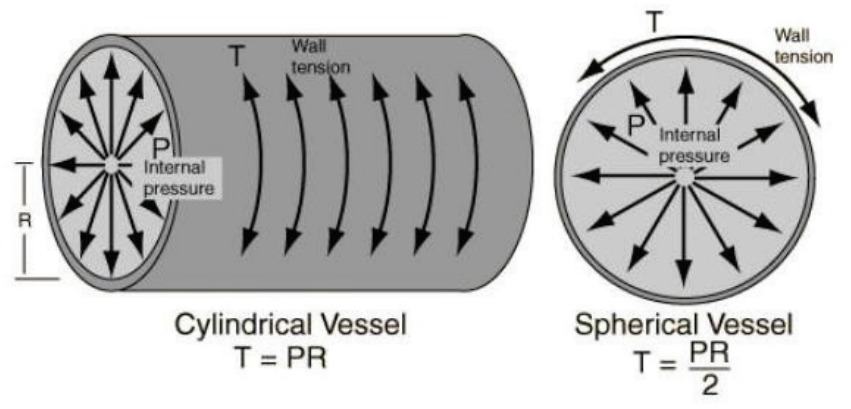

Figure 2. A schematic of the forces present in an artery according to the Laplace equation. ${ }^{22}$

\subsection{The Effect of Turbulent Flow}

In fluid motion, the behavior of individual particles with respect to the greater fluid is determined by inertial and viscous forces. Inertial force dictates the motion of a particle as an independent actor, and viscous force describes the cohesive attraction between particles of a fluid. The Reynolds number, $\left(R_{e}\right)$, is the product of a model which uses a fluids velocity $\left(v_{c}\right)$, diameter $(R)$, density $(\rho)$, and viscosity $(\eta)$ in order to predict whether the flow is of particles is disordered (turbulent) or neatly configured (laminar). For a cylindrical tube of diameter R, perhaps an aorta, laminar flow typically occurs with $R_{e}<2300$ and the onset of turbulent flow with $R_{e}>2600 .{ }^{23}$

$$
R_{e}=\frac{v_{c} R \rho}{\eta}
$$

When the viscous force outweighs the inertial forces, the fluid maintains strong cohesion, and laminar flow results. Laminar flow is defined as motion of a fluid in which the velocity components of every particle in the fluid is oriented towards the bulk motion. ${ }^{24}$ This type of flow is characterized by a parabolic velocity profile in which the fluid resistance is least in the center of the tube, with distinct layers or laminae which do not overlap (Figure 3a).

(a)

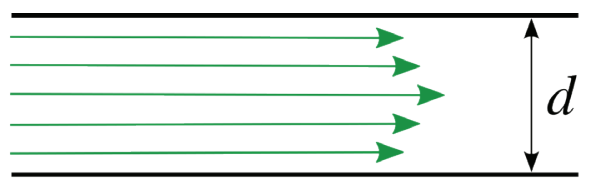

(b)

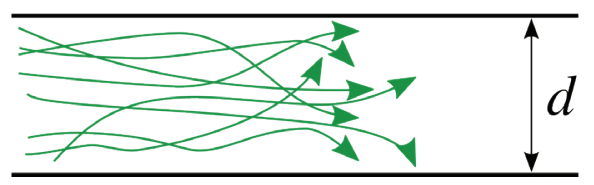

Figure 3. A depiction of laminar (a) and turbulent (b) flows, depending on Reynolds number. ${ }^{25}$
Conversely, when the inertial forces are dominant, turbulent flow results. This type of flow is characterized by randomly oriented velocity vectors of individual fluid particles, and a lack of distinct laminae (Figure 3b). Turbulent flow is of particular relevance to aortic aneurysms because the random collisions of particles against the containing wall cause a meaningful increase in pressure for every unit of distance traversed by the fluid, as characterized by the Hagen-Poiseuille model for laminar and turbulent flow (Figure 4).

While the Reynolds number equation cannot directly tie increased aortic diameter to turbulent flow-since $R_{e}$ is inversely related to diameter - there are mechanisms in which endothelial cells of the arterial tunica intima remodel biological structure in response to mechanical stress, resulting in turbulent arterial flow. ${ }^{26,27}$ Dilation of the aortic root may cause aortic valve regurgitation, which has been shown to cause turbulent aortic flow as well.

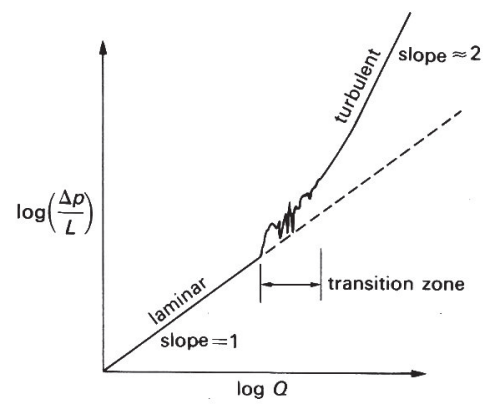

Figure 4. The Hagen-Poiseuille Model for Pressure vs. Flow in laminar and turbulent characterized fluids. ${ }^{28}$ Once a fluid reaches turbulence, there is a meaningful increase in pressure on the vessel.

\subsection{The Physical Approach in Summary}

Using the principle of continuity, Bernoulli equation, Laplace equation, and Reynolds number descriptor of turbulent flow, it has been theoretically asserted that the presence of an aneurysm begets its exacerbation. By initial dilation, the velocity in the aneurysmal region is decreased, resulting in an increase of pressure. Both an increased radius and increased pressure contribute to the tensile stress on the aortic wall, which causes the tissue to dilate further. More, dilation in a vessel may lead to intimal remodeling or aortic regurgitation, which also contribute to an increase in pressure and consequently to wall tension. Although this section provides a clear descriptor of the physical process of aneurysm growth, it does not explain the origin of a thoracic aortic aneurysm - why some individuals develop an aneurysm in 
their late teens while others live full lives with no pathological dilatation of their aorta whatsoever.

\section{Biological Basis of TAA Formation}

\subsection{Molecular Mechanisms of Hereditary Aneurysm Development}

While TAAs may present in various ways, the disorders most consistent in causing aortic aneurysms are Marfan syndrome (MFS) and Loeys-Dietz syndrome (LDS), which are classified as genetic connective tissue disorders. Phenotypically, MFS and LDS patients are fairly similar, both characterized by tall stature, scoliosis, ectopia lentis (dislocation of the ocular lens), and arachnodactyly (abnormally long fingers) and as such, LDS was once considered to be MFS "type 2." ${ }^{30}$ Further, the two diseases share genetic similarities, with respective mutations belonging to the same general cascade (Figure 6). MFS is defined by a Fibrillin-1 (FBN1) gene mutation, and LDS is comprised of four sub types, with mutually exclusive mutations of TGF- $\beta$ R 1 , TGF- $\beta$ R2, Smad3, and TGF- $\beta 2$, classified in that order as types I-IV.,.$^{9,12}$

The contribution of TGF $\beta$ signaling to MFS-specific TAA was first described by Neptune et al. who found that Fibrillin-1 deficient mice used to model MFS had a marked upregulation of TGF $\beta$ expression. ${ }^{8}$ More, it has been demonstrated that TGF $\beta$ antagonism, either through neutralizing antibody or Losartan, attenuates the phenotypic effects of MFS, including aortic aneurysm development, in both mice and humans. ${ }^{17,8,32,33,34}$

\subsection{Canonical and non-Canonical TGF $\beta$ Signaling}

TGF $\beta$ expression transduces canonical and non-canonical signaling pathways, characterized by Smad2/3 and ERK1/2 protein phosphorylation, respectively. ${ }^{35,36}$ Both p-Smad 2 and pERK1/2 have been shown to be significantly upregulated in the aortic media of Marfan murine models. ${ }^{32,37}$ More, Holm et al. found that inhibition of ERK1/2 in a murine MFS model resulted in attenuation of aneurysm development. ${ }^{37}$ In murine models which mimic LDS, studies have shown similar results: TGF $\beta, \mathrm{pSmad} 2$, and $\mathrm{pERK} 1 / 2$ were overexpressed, and aneurysmal dilatation was attenuated by Losartan, which had a therapeutic efficacy correlated with reduction of pSmad 2 and pERK $1 / 2$ in the aortic media. ${ }^{38}$ It would appear to be a simple case, then: TGF $\beta$, Smad, and ERK signaling are the drivers of aneurysm development, and the ideal pharmacological solution is an all-encompassing

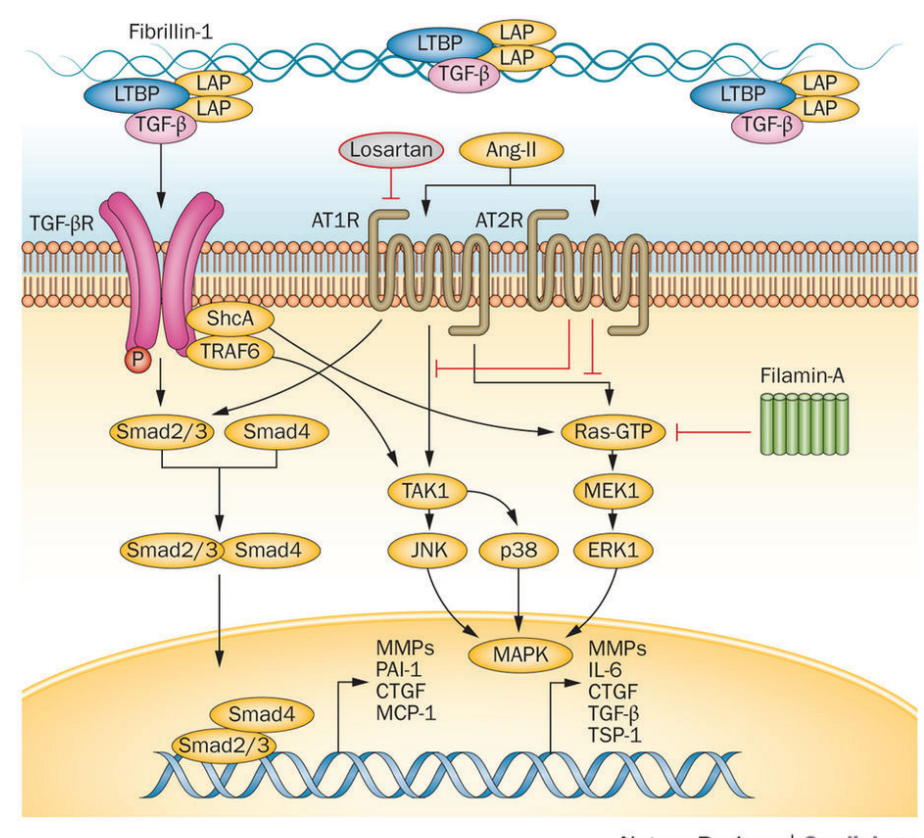

Nature Reviews | Cardiology

Figure 5. A relevant proposed mechanism for cardiovascular pathology in connective tissue disorders. The Fibrillin-1 mutation causes decreased binding of TGF $\beta$ to the Large Latent Complex (LLC), and subsequent increased binding to a TGF $\beta$ receptor, TGF $\beta \mathrm{R} 1$ or $\mathrm{TGF} \beta \mathrm{R} 2$. This process results in stimulation of the canonical and non-canonical TGF $\beta$ pathways. Canonical signaling is characterized by Smad2/3 and Smad4, and non-canonical by ERK1, Ras, TAK1, JNK, p38, MEK1, and MAPK. Both pathways result in alteration of transcription of characteristic genes. Losartan attenuates aortic aneurysm development via crosstalk between AT1R (Angiotensin II type 1 receptor) and AT2R (Angiotensin II type 2 receptor. ${ }^{31}$

blockade. However, the aforementioned studies are limited in that they lack assessment of the pathway in early development. Only association is proven, and at a late-stage of aneurysm development.

\subsection{Time Point as a Determinant of Molecular Role}

A landmark study by Cook et al. shows TGF $\beta$ antagonization to be detrimental at early time points, and describes ERK1/2 and Smad2 expression as neither paired nor linearly accumulated. ${ }^{39}$ Compared to wild-type (WT), pERK1/2 levels were significantly increased in MFS mice at all time points from $\mathrm{p} 16$ to $\mathrm{p} 60$, while $\mathrm{pSmad} 2$ was only significantly upregulated in MFS mice at p60. ${ }^{39}$ Treatment of Mgr mice (an established model of MFS with aggressive aneurysm 
development) at p16 with TGF $\beta$ neutralizing antibody exacerbated the aneurysm, resulting in early death; treatment at p45 was proven to be the optimal time for aneurysm attenuation..$^{40,39}$ As such, it cannot be unequivocally stated that $\mathrm{TGF} \beta$ signaling is causal of aneurysm development, and this study suggests that $\mathrm{TGF} \beta$ and $\operatorname{Smad} 2$ signaling may hold a protective role in aneurysm development.

Approaching the canonical pathway from a different approach, the Fischbein group has investigated miR-29b, a microRNA shown to repress Smad2 signaling through TGF $\beta 1 .{ }^{41}$ They have shown that miR-29b contributes to early aneurysm development in MFS, first by asserting its overexpression compared to WT at weeks 2 and 4, and normalization by week $8 .{ }^{42}$ Further, continued inhibition of miR-29b from early development until sacrifice attenuates aneurysmal dilatation in MFS mice. ${ }^{43}$ Interestingly, and perhaps not coincidentally, Smad2 signaling in MFS mice increases gradually from p16 until until a point of significant upregulation versus WT mice at p60, where miR-29b levels become normalized in MFS mice. ${ }^{39,42}$ These findings further suggest a protective and compensatory role for Smad2 in MFS aneurysm development.

\subsection{Manipulations of the TGF $\beta$ Pathway in Murine Models Question its Role in Aneurysm Development}

Several investigators have constructed murine models with various manipulations to the TGF $\beta$ pathway to challenge the notion that overexpression of TGF $\beta$ is the dominant contributor to aneurysm development. The results were sweepingly definitive: two postnatal deletion models of TGF $\beta$ R2, a TGF $\beta 2$ loss-of-function mutation model, and a joint MFS-TGF $\beta$ R2 deletion model all depicted severely enhanced aortopathy. ${ }^{44,45,46}$ These results are contrary to previous research, and show that ablation of TGF $\beta$ signaling, from early development and throughout life, does not attenuate aneurysm development. More, deletion of TGF $\beta$ R2 in cell culture significantly reduces ERK $1 / 2$ and Smad 2 phosphorylation, further complicating the presumed simple correlation of canonical and non-canonical signaling with aneurysm development. ${ }^{45}$

It has further been found that $\operatorname{Smad} 3$ holds a critical role in maintaining vessel integrity, with its knockout in an otherwise normal mouse resulting in extreme vessel remodeling and dilatation. ${ }^{47}$ Similar results in FBN1 mutant mice (MFS model) have led researchers to believe that canonical Smad signaling may in fact be a protective and compensatory response to biological dysfunction or mechanical stress. ${ }^{48}$ Con- versely, blockade of non-canonical ERK signaling has been shown to have attenuating effects on TAA development. ${ }^{15}$

\section{Bicuspid Aortic Valve: a Joint Approach}

Bicuspid Aortic Valve (BAV) is a disorder in which the aortic valve has two, instead of three, leaflets. It is common, with an incidence between 5 to 14 in 1000, and is predominantly associated with males, with a 3:1 ratio of male to female patients presenting with BAV..$^{49}$ It is a rather silent disease, with symptoms typically only manifesting in patients well into adulthood. More, it is a commonly associated with TAA, with one study finding nearly $20 \%$ of patients presenting with TAA as having an accompanying bicuspid aortic valve. ${ }^{49}$ Though BAV is associated with TAA, its pathophysiological mechanism is less understood than that of connective tissue disorders, and is complicated by an incidence of only $9 \%$ of BAV patients showing a genetic basis to their disease. ${ }^{50}$ There are three general sub types, categorized by the number of raphes, or fusions, between cusps of the aortic valve.

Type 0 has no raphes, and consists of two semi-circular

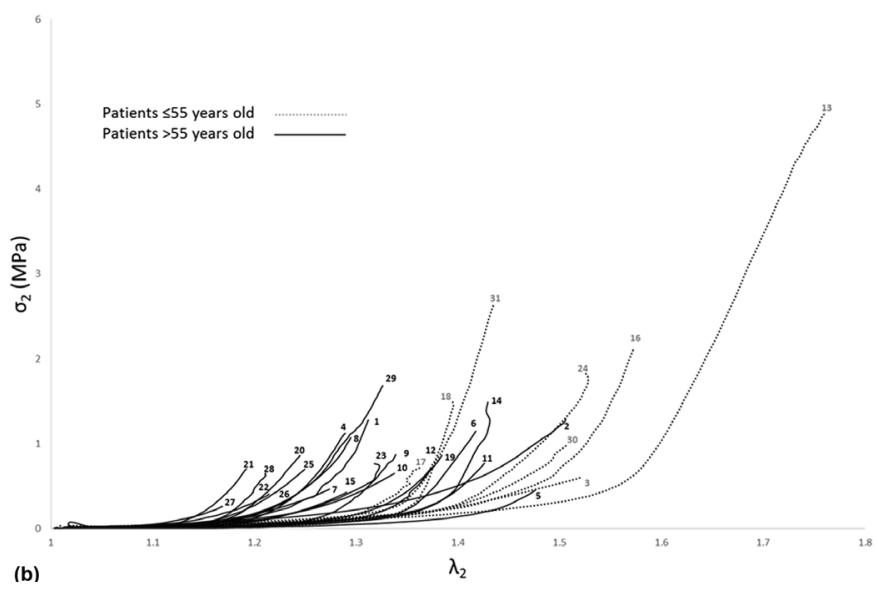

Figure 6. An axial stress-strain curve of aneurysmal ascending aortic tissue, brought to breaking point. Stress-Strain curves are used to characterize the elastic and plastic physical properties of materials. Stress, $\sigma$, is the applied force per area of application. Strain, $\varepsilon$, is the fractional change in material length. Together, these metrics can predict the flexibility, brittleness, or breaking point of materials. This is of particular importance to the study of diseased aortas and their propensity for dissection. ${ }^{15}$ 
valves. Type 1 holds one fusion, and can occur at three locations (left/right, right/non, or left/non fusion). Type 2 consists of two fusions..$^{51}$ Due to the apparent lack of genetic play in the aneurysm development, the distinct aortic hemodynamic profile of BAV patients, and the finding that BAV patients with more severe aortic regurgitation had larger aortic dimensions, the aneurysm development is largely attributed to physical stress on the tissue. ${ }^{52}$

With evidence pointing towards a model of mechanical stress as the driver of aneurysm development, researchers have pursued techniques of assessing hemodynamic profiles (via aortic regurgitation and stenosis), and strength testing of the aortic via stress-strain breaking points. ${ }^{52,15}$ Duprey et al. notably found that aortic capacity to absorb stress decreases with age, leading to the conclusion that collagen remodeling in the aortic elastic lamina may scale with age - an important factor for predicting when to operate on TAA patients. ${ }^{15}$

\section{Concluding Remarks}

The thoracic aortic aneurysm is a common yet severe disease. It may be linked to various hereditary disorders, the presence of a BAV, or be entirely non-syndromic., ${ }^{921}{ }^{12}$ There are various ways to explain the development of the aneurysm, using biological methods to disrupt specific signaling cascades, or physical methods to asses the hemodynamic and material profiles of diseased aorta. ${ }^{37,48,49,15}$ Further, the physical effects of vessel dilatation may be understood conceptually using various well-established models, such as the Principle of Continuity, Bernoulli equation, and Laplace equation. Combining the aforementioned biological, biophysical, and physical interpretations allows for a more comprehensive understanding of TAA pathophysiology.

\section{Acknowledgments}

We would like to give special thanks to Dr. Albert "AJ" Pedroza for continued support and intellectual discussion on the topic.

\section{References}

1. Finlayson J. On the Occurrence of a Diastolic Murmur of Aortic Origin Apart from Aortic Incompetency or Aneurysm. The British Medical Journal 1, 426-427 (1885).

2. Itani $\mathrm{Y}$, Watanabe $\mathrm{S}$, Masuda $\mathrm{Y}$, Hanamura $\mathrm{K}$, Asakura K, Sone S, Sunami Y, Miyamoto T. Measurement of aortic diameters and detection of asymptomatic aortic aneurysms in a mass screening program using a mobile helical computed tomography unit. Heart Vessels 16, 42-5 (2003).

3. Kalsch H, Lehmann N, Mohlenkamp S, Becker A, Moebus S, Schmermund A, Stang A, Mahabadi AA, Mann K, Jockel KH, Erbel R, Eggebrecht H. Body-surface adjusted aortic reference diameters for improved identification of patients with thoracic aortic aneurysms: Results from the population-based Heinz Nixdorf Recall study. International Journal of Cardiology 163, 72-8 (2013).

4. Roman MF, Devereux RB, Kramer-Fox R, O’Loughlin J. Two-dimensional echocardiographic aortic root dimensions in normal children and adults. Am J Cardiol 64, 507-12 (1989). JAMA 280, 1926-1929 (1998).

5. Gregory A, Kuzmik BA, Adam X, Sang BA, John A, Elefteriades MD. Natural history of thoracic aortic aneurysms. Journal of Vascular Surgery 56, 565-571 (2012).

6. Daput OE et al. The natural history of thoracic aortic aneurysms. Journal of Thoracic and Cardiovascular Surgery 107, 1323-1333 (1994).

7. Cronenwett JL, Johnston KW. Rutherford's vascular surgery, Elsevier Health Sciences. Philadelphia (2014)

8. Neptune ER, Frischmeye PA, Arking DE, Myers L, Bunton TE, Gayraud B, Ramirez F, Sakai LY, Dietz HC. Dysregulation of TGF-beta activation contributes to pathogenesis in Marfan syndrome. Nat. Genet. 33,407-11 (2003).

9. Loeys BL, Schwarze U, Holm T, Callewaert BL, Thomas GH, Pannu H, De Backer JF, Oswald GL, Symoens S, Manouvrier S, Roberts AE, Faravelli F, Greco MA, Pyertiz RE, Milewicz DM, Coucke PJ, Cameron DE, Braverman AC, Byers PH, De Paepe AM, Dietz HC.. Aneurysm syndromes caused by mutations in the TGF-beta receptor. New Engl J Med 355, 788-798 (2006).

10. Gelb BD. Marfan's syndrome and related disorders more tightly connected than we thought. New Engl $J$ Med 355, 841-44 (2006).

11. Judge DP, Dietz HC. Marfan's syndrome. Lancet 366, 1965-76 (2005).

12. Ramirez F, Dietz HC. Marfan syndrome: from molecular pathogenesis to clinical treatment. Curr. Opin. Genet. Dev. 17, 252-258 (2007).

13. Oliver JM, Gallego P, Gonzalez A, Aroca A, Bret M, Mesa JM. Risk factors for aortic complications in 
adults with coarctation of the aorta. J. Am. Coll. Cardiol. 44, 1641-1647 (2004).

14. Akerman A et al. Elevated Wall Tension Initiates Interleukin-6 Expression and Abdominal Aortic Dilation. Annals of Vascular Surgery 41, 24-25 (2017).

15. Duprey A, Trabelsi O, Vola M, Favre JP, Avril S. Biaxial rupture properties of ascending thoracic aortic aneurysms. Acta Biomateriala 42 273-285 (2016).

16. Sassani SG, Kakisis J, Tsangaris S, Sokolis DP. Layer-dependent wall properties of abdominal aortic aneurysms: Experimental study and material characterization. J. Mech. Be. Biom. Mat. 49, 141-161 (2015).

17. Lacro RV, et al. Atenolol versus Losartan in Children and Young Adults with Marfan's Syndrome. New England Journal of Medicine 371, 2061-2071 (2014).

18. H. Eggebrecht, J. Barkhausen, and K.-F. Kreitner. Diseases of the Thoracic Aorta. Cardiac Imaging 264-71 (2009).

19. Gregory Falkovich. 2011. Fluid Mechanics: A Short Course for Physicists. Weizmann Institute of Science, Israel.

20. Johnson, RW. 2016. Some reflections on the history of fluid dynamics. CRC Press, Florida.

21. Schmidt-Nielsen, K. 1990. Animal Physiology: Adaptation and environment. Cambridge University Press, Cambridge.

22. Nave, R. The Baby's First Breath. Pressure, hyperphysics.phy-astr.gsu.edu/hbase/ptens3.html.

23. Schlichting H, Gersten, K. 2017. Boundary-Layer Theory. Springer-Verlag Berlin Heidelberg. Berlin.

24. Warhaft Z. The Engine and the Atmosphere: An Introduction to Engineering. Cambridge University Press, 1997.

25. Paumier, G. Laminar and turbulent flows, depending on the Reynolds number. https://www.elveflow.com/ microfluidics-applications/fluid-handling/microfluidics-turbulent-vs-laminar-flow/.

26. Nerem RM, Harrison DG, Taylor WR, Alexander RW. Hemodynamics and vascular endothelial biology. $J$. Cardiovasc. Pharmacol. 21, s6-s10. (1993).

27. Michiels C. Endothelial cell functions. Journal of Cellular Physiology 196, 430-443 (2003).

28. Parker, K. Mechanics of the Circulation. Chapter 5. Imperial College London, Department of Bioengineering.

29. Carr-White GS, Afoke A, Birks EJ, Hughes S, O'Halloran A, Glennen S, Edwards S, Eastwood M, Yacoub MH. Aortic Root Characteristics of Human Pulmonary
Autografts. Circulation 102, 15-21 (2000).

30. Pyeritz RE. Marfan syndrome: improved clinical history results in expanded natural history. Genetics in Medicine (2018).

31. Levine RA et al. Mitral valve disease-morphology and mechanisms. Nature Reviews Cardiology 12, 689710 (2015).

32. Habashi JP, Judge DP, Holm TM, Cohn RD, Loeys BL, Cooper TK, Myers L, Klein EC, Liu G, Calvi C, Podowski M, Neptune ER, Halushka MK, Bedja D, Gabrielson K, Rifkin DB, Carta L, Ramirez F, Huso DL, Dietz HC. Losartan, an AT1 antagonist, prevents aortic aneurysm in a mouse model of Marfan syndrome. Science 312, 117-21 (2006).

33. Ng CM, Cheng A, Myers LA, Martinez-Murillo F, Jie C, Bedja D, Gabrielson KL, Hausladen JM, Mecham RP, Judge DP, Dietz HC. TGF-beta-dependent pathogenesis of mitral valve prolapse in a mouse model of Marfan syndrome. Clin. Invest. 114, 1586-92 (2004).

34. Brooke BS, Habashi JP, Judge DP, Patel N, Loeys B, Dietz HC. Angiotensin II blockade and aortic-root dilation in Marfanâ€ $€^{\mathrm{TM}_{\mathrm{S}}}$ syndrome. New. Engl. J. Med. 358, 2787-95 (2008).

35. Kang JS, Liu C, Derynck R. New regulatory mechanisms of TGF-Î ${ }^{2}$ receptor function. Trends in Cell Biology 19, 385-94 (2009).

36. Derynck R, Zhang YE. Smad-dependent and Smad-independent pathways in TGF-beta family signalling. Nature 425, 577-84 (2003).

37. Holm TM, Habashi JP, Doyle JJ, Bedja D, Chen Y, van Erp C, Lindsay ME, Kim D, Schoenhoff F, Cohn RD, Loeys BL, Thomas CJ, Patnaik S, Marugan JJ, Judge DP, Dietz HC. Noncanonical TGFB signaling contributes to aortic aneurysm progression in Marfan syndrome mice. Science, 332 358-61 (2011).

38. Gallo EM, Loch DC, Habashi JP, Calderon JF, Chen Y, Bedja D, van Erp C, Gerber EE, Parker SJ, Sauls K, Judge DP, Cooke SK, Linsday ME, Rouf R, Myers L, ap Rhys CM, Kent KC, Norris RA, Huso DL, Dietz HC. Angiotensin II-dependent TGF-Î̃ ${ }^{2}$ signaling contributes to Loeys-Dietz syndrome vascular pathogenesis. J. Clin. Invest. 124, 448-60 (2014).

39. Cook JR, Clayton NP, Carta L, Galatioto J, Chiu E, Smaldone S, Nelson CA, Cheng SH, Wentworth BM, Ramirez F. Dimorphic Effects of Transforming Growth Factor- $\hat{I}^{2}$ Signaling During Aortic Aneurysm Progression in Mice Suggest a Combinatorial Therapy for Marfan Syndrome. Arterioscler. Thromb. Vasc. 
Biol. 35, 911-17 (2015).

40. Pereira L, Lee SY, Gayraud B, Andrikopoulos K, Shapiro SD, Bunton T, Biery NJ, Dietz HC, Sakai LY, Ramirez F. Pathogenetic sequence for aneurysm revealed in mice underexpressing fibrillin-1. Proc. Natl. Acad. Sci. USA. 96, 3819-23 (1999).

41. Li J, Cen B, Chen S, He Y. MicroRNA-29b inhibitis TGF-I ${ }^{2} 1$-induced fibrosis via regulation of the TGF- $\hat{I}^{2} 1 /$ Smad pathway in primary human endometrial stromal cells. Molecular Medicine Reports 13, 4229-37 (2016).

42. Merk DR, Chin JT, Dake BA, Maegdefessel L, Miller MO, Kimura N, Tsao PS, Iosef C, Berry GJ, Mohr FW, Spin JM, Alvira CM, Robbins RC, Fischbein MP. miR-29b participates in early aneurysm development in Marfan syndrome. Circulation Research 110, 312 24 (2012).

43. Okamura H, Emrich F, Trojan J, Chiu P, Dalal AR, Arakawara M, Sato T, Penov K, Koyano T, Pedroza A, Connolly AJ, Rabinovitch M, Alviroa C, Fischbein MP. Long-term miR-29b suppression reduces aneurysm formation in a Marfan mouse model. Physiol. Rep. 5, Epub (2017).

44. Wei H, Hu JH, Angelov SN, Fox K, Yan J, Enstrom R, Smith A, Dichek DA. Aortopathy in a mouse model of Marfan syndrome is not mediated by altered transforming growth factor $\hat{\mathrm{I}}^{2}$ signaling. J. Am. Heart. Assoc. 6, Epub (2017).

45. Hu JH, Wei H, Jaffe M, Airhart N, Du L, Angelov SN, Yan J, Allen JK, Kang I, Wight TN, Fox K, Smith A, Enstrom R, Dichek DA. Postnatal deletion of the type II transforming growth factor- $\hat{\mathrm{I}}^{2}$ receptor in smooth muscle cells causes severe aortopathy in mice. Arterioscler. Thromb. Vasc. Biol. 35, 2647-56 (2015).

46. Lindsay ME, Schepers D, Bolar NA, Doyle JJ, Gallo E, Fert-Bober J, Kempers MJE, Fishman EK, Chen Y, Myers L, Bjeda D, Oswald G, Elias AF, Levy HP, Anderlid BM, Yang MH, Bongers EM, Timmermans
J, Braverman AC, Canham N, Mortier GR, Brunner HG, Byers PH, Eyk JV, Laer LV, Dietz HC, Loeys BL. Loss-of-function mutations in TGFB2 cause a syndromic presentation of thoracic aortic aneurysm. $\mathrm{Na}$ ture Genetics 44, 922-7 (2012).

47. Dai X, Shen J, Annam NP, Jiang H, Levi E, Schworer CM, Tromp G, Arora A, Higgins M, Wang X, Yang M, Li HJ, Zhang K, Kuivaniemi H, Li L. SMAD3 deficiency promotes vessel wall remodeling, collagen fiber reorganization and leukocyte in infiltration in an inflammatory abdominal aortic aneurysm mouse model. Scientific Reports 5, 10180 (2015).

48. Pedroza AJ, Koyano TK, Trojan JD, Palmon I, Arakawa M, Penov K, Fischbein MP. Extracellular Signal-related Kinase Signaling and Smooth Muscle Cell Contractile Gene Expression are Uniformly Enhanced in the Aortic Root and Ascending Aorta in Marfan Syndrome. Circulation 132, A18897 (2015).

49. Otto C, Bonow R, Braverman AC, Beardslee MA. The bicuspid aortic valve. In: Otto $\mathrm{C}$, Bonow $\mathrm{R}$, eds. Valvular heart disease: a companion to Braunwald's heart disease. Philadelphia: Saunders/Elsevier 169-86 (2009).

50. Huntington K, Hunter AGW, Chan KL. A prospective study to assess the frequency of familial clustering of congenital bicuspid aortic valve. J. Am. Coll. Cardiol. 30, 1809-1812 (1997).

51. Sievers HH, Schmidtke C. A classification system for the bicuspid aortic valve from 304 surgical specimens. Journal of Thoracic and Cardiovascular Surgery 133, 1226-33 (2007).

52. Della Corte A, Bancone C, Quarto C, et al. Predictors of ascending aortic dilatation with bicuspid aortic valve: a wide spectrum of disease expression. Eur. J. Cardiothorac. Surg. 31, 397-405 (2007). 